\title{
FEATURES OF THE USE OF UNMANNED AERIAL VEHICLES FOR AGRICULTURE APPLICATIONS
}

\author{
Aleksandrs Urbahs, Ieva Jonaite \\ Institute of Aeronautics of Riga Technical University, Kalku Street 1, 1658 Riga, Latvia \\ E-mail: aerti@rtu.lv (corresponding author)
}

Received 20 September 2013; accepted 20 November 2013
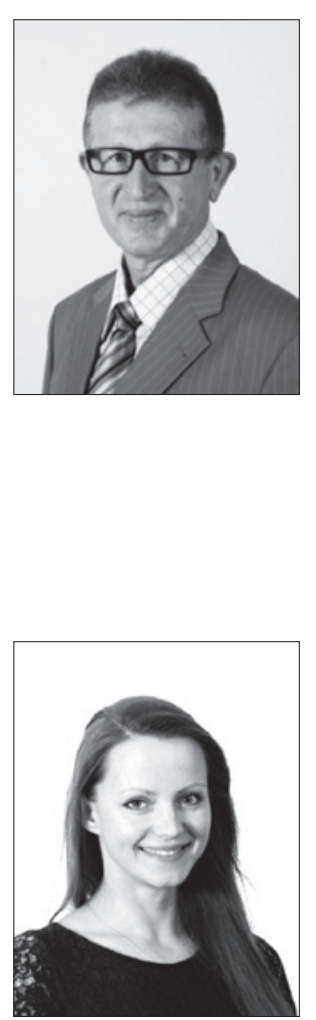

Aleksandrs Urbahs, Professor, Dr. Habil. Sc.Eng.

Date of birth: 1958

Education: 1981 - Diploma of Mechanical Engineer, Riga Civil Aviation Engineering Institute, Faculty of Mechanical Engineering. 1986 - Dr. sc.ing., Riga Civil Aviation Engineering Institute, Faculty of Mechanical Engineering. 1997 - Dr. hab. sc.ing., Riga Aviation University. Affiliations and functions: 1989-1999 - Vice Dean and Dean, Faculty of Mechanical Engineering, Riga Aviation University. Since 1999 - Full time Professor, Riga Technical University. 1999-2012 Director of the Institute of Transport Vehicles Technologies of Riga Technical University. Since 2012 - Director of the Institute of Aeronautics of Riga Technical University. Research interest: Aeronautics, Transport and Mechanical Engineering, Unmanned Vehicles, Nano-Materials, Non destructive methods of control.

Publications: 315 scientific papers and 19 patents.

Present position: Professor, Director of the Institute of Aeronautics of Riga Technical University, Expert at Latvian Council of Science ect.

Ieva JONAITE, MSc. Eng.

Date of birth: 1984.

Education: 2004-2008 - professional bachelor, Material Design and Technology, Riga Technical University; 2009-2012 - professional master, Transport System Engineering, Riga Technical University; 2013 - doctoral student at Riga Technical University. Affiliations and functions: 2009-2012 project administrator, 2011-2012 research assistant in research projects.

Research interest: unmanned aerial vehicles, wearable electronics, and smart textiles. Present position: 2012 - scientific assistant to the rector of Riga Technical University.

Abstract. Micro-UAVs (unmanned aerial vehicles) with a total weight below $5 \mathrm{~kg}$ are interesting alternative carriers for agricultural applications. Compared to standard airborne aerial surveys, UAVs are much more flexible and weather independent. As a result, micro-UAV surveys will pave the way for affordable, current and accurate geo-information. This article deals with the general conditions and challenges for unmanned aerial vehicles that can be used for agricultural land monitoring. The article includes an overview of the structural characteristics and parameters of a UAV that has been developed for environmental monitoring by the Institute of Transport Vehicle Technology of Riga Technical University, and a detailed review about surveying fields with UAV systems is carried out.

Keywords: unmanned aerial systems, monitoring, agriculture.

\section{Introduction}

Environmental monitoring (ecological monitoring) is a complex system to monitor and assess environmental conditions and forecast the effects of natural and anthropogenic factors. Agricultural land monitoring is an important part of environmental monitoring. At the same time, national land monitoring is an essential component of total national ecological security and national functions in the ecological system. 
To ensure an effective monitoring process, it is necessary to have new equipment and technologies, monitoring systems, and data acquisition and processing systems, including those that work with remotely sensed data, which is currently the most objective and fastest in use. Remote sensing applications for agriculture often require images with a high temporal resolution. Satellite imagery and controlled aircraft data are quite difficult to obtain and the price is too high, which is why this data is not available to most, Furthermore, it is often quite outdated. Unmanned drones equipped with GPS and digital cameras have therefore become a focus of research all around the world. The autonomous navigation of a UAV is realised using GPS, inertial measuring techniques, and other sensors. The programmable autopilot enables serious photogrammetric work, thus enabling systematic, rapid and efficient mapping of areas of interest.

Unmanned aircraft systems are mostly being used for military applications (more than $80 \%$ ), but in recent years particular attention has been paid to the integration of UAVs into the civil sector, especially in nature conservation and forested, agricultural, etc. areas (Urbahs et al. 2008; Grenzdorffer et al. 2008).

\section{Application and main challenges}

The UAS (unmanned aerial system) micro-class demonstrates much promise for use in agriculture.

The main tasks for agricultural land monitoring by unmanned aerial systems are:

- determination of the land occupied by crops;

- determination of crop condition;

- identification of crop infestation;

- identification of crop damaged by natural phenomena (hail, rain, storm, drought, fire);

- quick assessment of vegetation condition and biomass yield;

- initial assessment and forecasting of yield;

- observation of harvest work;

- evaluation of the soil condition for the next season, etc.

All the aforementioned fields of application are characterised by their relatively small scale (less than 1,500 ha) and the necessity for rapid data availability and analysis. The required absolute positional accuracy is on the other hand quite low $(<1 \mathrm{~m})$. Beside a visual analysis of images, many of the aforementioned applications require images to be integrated as georeferenced and orthorectified products in a GIS (geographical information system) for analysis with other GIS data (Grenzdorffer et al. 2008).

UAVs have acquired particular importance in this sector through precision agriculture (PA). In recent years, precision agriculture has gained a great deal of attention in agriculture. It is recognised that PA or the 'precision approach', which means the right action in the right place and at the right time, is the most effective way to accelerate the comprehensive development of agriculture (Fig. 1) (Vilde et al. 2008).

PA is a type of field management, which thanks to the new technologies, machinery and equipment options using GPS technology allows one to identify, analyse and react quickly to the qualitative characteristics of a cultivated land area and apply the most appropriate farming system (soil tillage, fertilisation, choice of varieties, etc.). Precision agriculture is closely related with the development of technology dealing with acquiring, processing and analysing the necessary data, making decisions, and developing and implementing solutions.

The incorporation of more complicated unmanned systems, including aerial vehicles, is a growing trend in agriculture, enabling precise crop management that can save farmers a lot of money in time and resources and opening up new, innovative research that could blaze new trails in agriculture and agronomics.

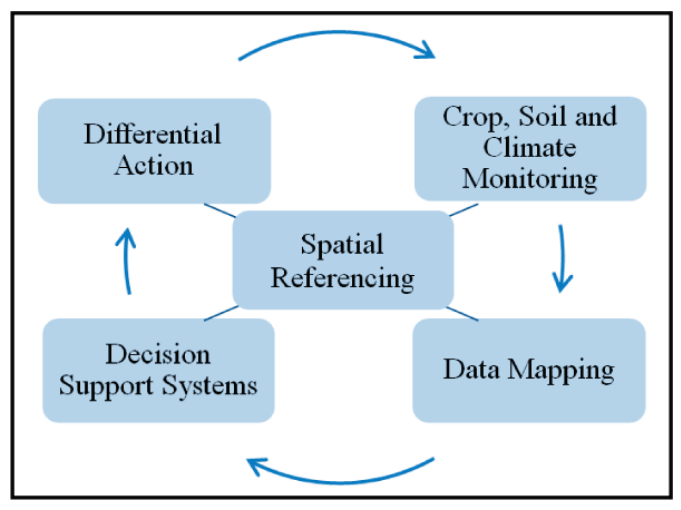

Fig. 1. Idea of precision agriculture

\section{Advantages of UAV system}

As mentioned before, one of the cheapest and most promising types of agricultural land monitoring is the use of UAVs. Small drones have several advantages over traditional aerial photography systems and satellites. Photographs taken by UAVs are accessible on demand and provide full spatial coverage without interference from clouds. These unmanned systems can provide very high image resolution: up to $2 \mathrm{~cm}$ if necessary. Compared with satellites, UAV do not have any minimal area restrictions for picture taking. The difference between a pilot-controlled aircraft and a UAV is that a UAV mission takes much less time due to manoeuvrability and the craft can provide high-quality image acquisition in hard-to-reach areas.

The main advantages of the use of unmanned aerial systems are:

- accessibility (use of the system is less expensive than other alternatives); 
- flexibility (easily exploitable, can change mission settings and purpose any time, fast data transmission, and can be equipped with different types of devices);

- efficiency (can carry out different kinds of missions with fewer resources and can ensure high quality output data).

\section{UAV design features}

The design features of any kind of UAV depend on its intended use. Construction of a remotely controlled UAV has to take into account several specific requirements, including flexible manufacturing technologies, reliable and safe exploitation, ecological safety, etc. Depending on the purpose and the executable functions of the UAV, it is extremely important to take the right decisions regarding the design, weight and materials used for the construction of the UAV. It is necessary to ensure successful UAV take-off and landing when there is no runway and the possibility to control the UAV manually and in automatic mode with the use of modern navigation system and connection tools. The UAV must also be ecologically friendly, produce a minimal level of noise, etc.

Currently in Latvia, the Institute of Transport Vehicle Technology of Riga Technical University is actively working to develop UAV systems for environmental monitoring.

The following principal functions have been identified as a guide for the construction of the UAV:

- environmental monitoring;

- protecting strategic objects and nature preserves;

- determining the exact location of a target;

- detecting and mapping seats of fire and contaminated environmental zones;

- patrolling to aid the national armed forces and police;

- performing meteorological research, etc.

In addition, in the process of designing, a number of specific requirements have also been taken into account and include:

- performance (the ability of the UAV to take-off and land even when there is no runaway, simplicity of maintenance and repair, etc.);

- ecological safety requirements (does not contaminate the environment, minimum noise level, etc.);

- effective steerability (possibility of controlling the UAV both in manual and automatic mode using modern navigation systems and communication facilities).

The UAV is made according to the classical scheme, with an electric engine and pulling-type propeller. The UAV is equipped with special capsules for its payload (Fig. 2).

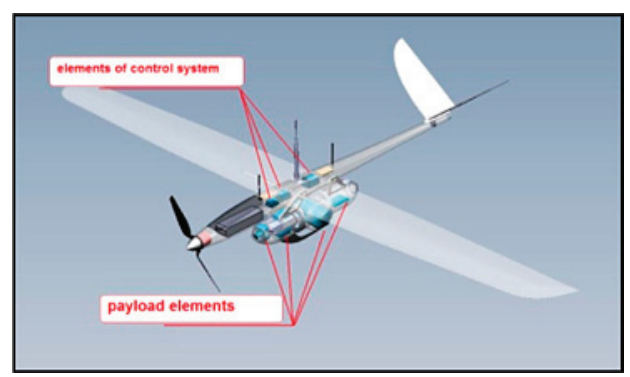

Fig. 2. Design layout of UAV (Urbahs et al. 2008)

The UAV is characterised by the following key features:

- weight - $2.5 \mathrm{~kg}$;

- flight duration - up to 1 hour;

- flight altitude - up to $3 \mathrm{~km}$;

- payload - up to $1.5 \mathrm{~kg}$;

- engine type - electric.

In the construction of the UAV, various types of innovative materials are used, but the main load-carrying structure is made from special extra-strong carbon tubes.

The UAV can execute environmental monitoring and with high accuracy spot the location of different objects and targets. One of the main UAV specifics is the application of two independent cylinders in one suspension system. The navigation camera in the front arc of visibility is designed for piloting the vehicle. This camera is stable and transmits an online picture (Fig. 2) to the ground control station. With a help of the navigation camera, it is possible to control the UAV and perform monitoring and target detection (for a screen shot from the navigation camera (Fig. 3).

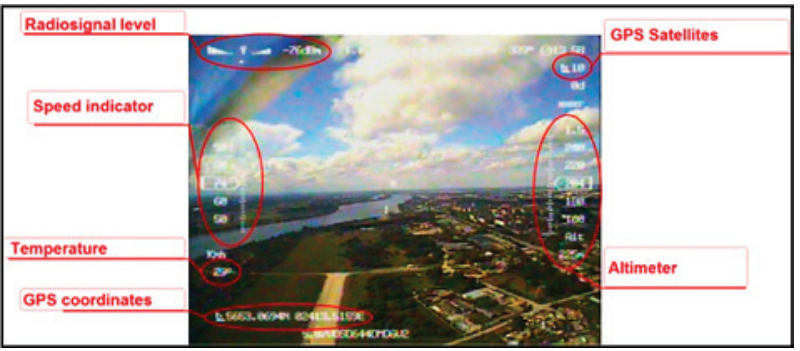

Fig. 3. View from UAV navigation camera while in flight

The second camera is high-resolution and can be rotated, which is suitable for taking photographs and capturing video of objects in zoom mode (Urbahs et al. 2008).

In order to ensure the fulfilment of the key functions, the UAV is equipped not only with a good video system, but also with GPS and autopilot. According to given coordinates, the UAV must carry out field surveys and on-demand should provide high quality and georeferenced (corresponding latitude, altitude, longitude) photography. 
It is also important for the unmanned aerial vehicle to remain simple and easily exploitable.

Depending on the given tasks, the UAV can be equipped with different types of devices such as:

- temperature sensors;

- electrochemical sensors;

- radiation sensors;

- near infrared camera.

\section{Field monitoring}

The use of UAVs for agricultural monitoring is effective due to its capabilities: easy and fast mission design, the re-usability of the platform, cost-effectiveness, and the existence of open-framework avionics packages specifically designed for UAVs, allowing them to be redesigned for different missions by simple parameterisation.

Using unmanned aerial systems for monitoring purposes ensures quick and effective surveillance of large areas. A UAV equipped with autopilot on a preplanned route with a fixed time interval can take photos from the air.

Monitoring agricultural land with an unmanned aerial vehicle is a system composed of several stages. These stages can be divided into two groups as shown below (Information ... 2011).

UAV Image Acquisition

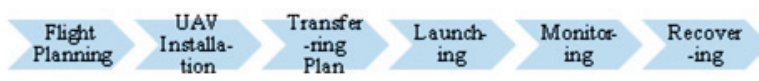

Image Processing

\begin{tabular}{l|ll} 
Raw Images & $\begin{array}{l}\text { Mosaic/ } \\
\text { Stitching }\end{array}$ Tiling $>\begin{array}{c}\text { Overlaying } \\
\text { Registration }\end{array}$
\end{tabular}

\subsection{Flight planning}

For this stage, there is specially designed flight planning software that allows quick and easy development of a flight plan for the area that is to be covered (Figs 4-5).

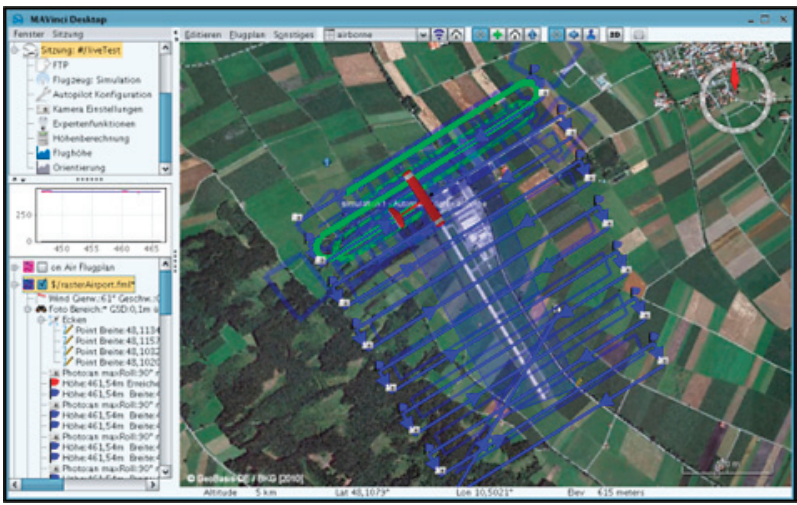

Fig. 4. Flight planning with picture area from MAVinci Desktop flight planning software (Images ... 2011)

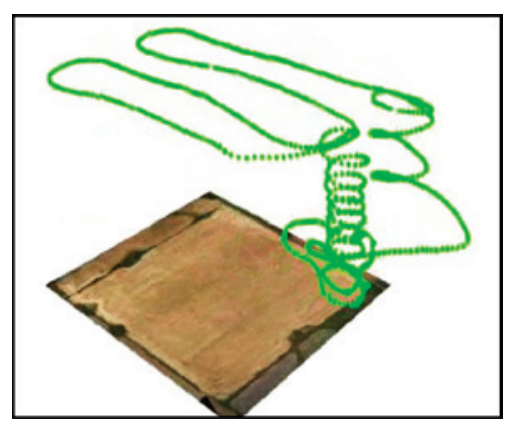

Fig. 5. Three-dimensional flight circuit example (Images ... 2011)

Based on the location of the selected area, first the main geographical coordinates of the field covering the entire surveyed area must be entered. Then, based on the primary objective of the mission and vehicle manoeuvrability, a flight network, the UAV track, is created. The desired flight can also be planned with single waypoints (Fig. 6).

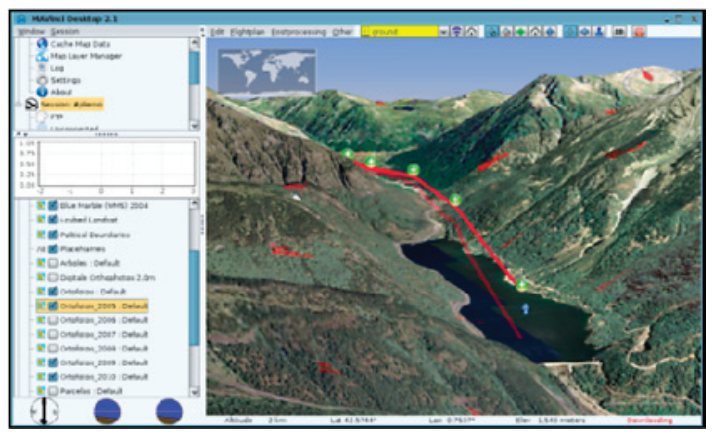

Fig. 6. Flight planning with single waypoints from MAVinci Desktop flight planning software (Images ... 2011)

At this stage, flight altitude and speed, required resolution, the number of images to be taken, etc. are specified.

When choosing software, several features must be taken into account:

- simple flight plan development and modification before or during the flight;

- flight tracking and control;

- full 3D and 2D view;

- waypoints can be edited while the aircraft is airborne;

- camera control;

- visualisation of the area covered by the aerial images;

- all health data such as battery voltage is visualised;

- compatible with different operation systems;

- data integration with other systems;

- offline mission planning;

- replay of flights, etc. 


\subsection{Mission performance and data synchronisation}

After the flight plan is developed, the flight is organised. The vehicle is transported to the mission start point. On average, the UAV is launched manually and automatic flight plan implementation begins at the moment when it reaches the first waypoint marked in the flight plan. Mission performance according to the flight plan can be controlled from a laptop. Depending on the situation, modifications can be made to the pre-made flight plan.

Data synchronisation is made after the flight; all the photos are loaded in software, where they are further processed.

\subsection{Data processing}

Usually there are a large number of images taken during the flight, and without proper processing, they are difficult to use for analysis.

Each image is obtained with the corresponding geographical coordinates (latitude, altitude, longitude). Specially designed software is able to collect these photos into one large orthographic image that can be used for further data analysis (Figs 7-9). The software's main tasks are:

- image orientation;

- automatic aerial triangulation;

- generation of surface model;

- creation of image mosaic;

- colour balancing;

- data preservation in the required format, etc.

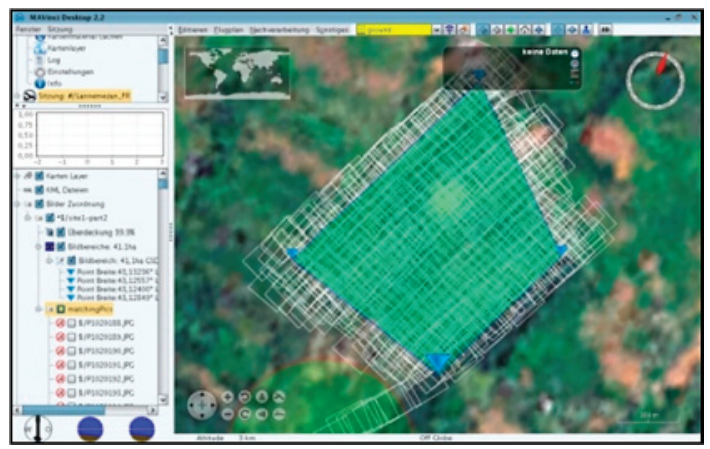

Fig. 7. Imported picture positions after the flight from MAVinci Desktop flight planning software (Images ... 2011)

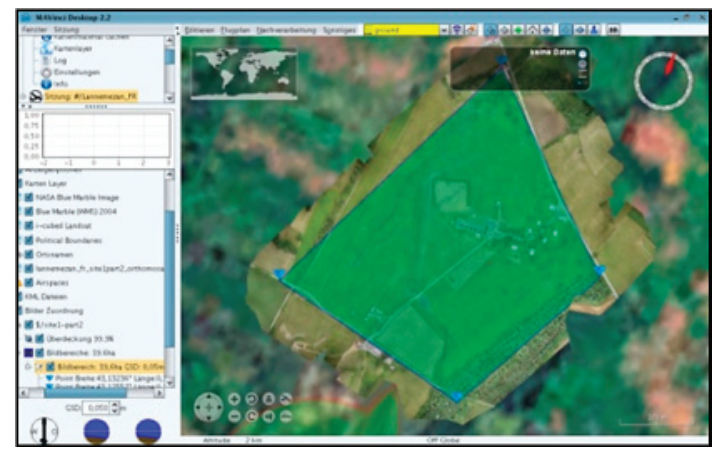

Fig. 8. Imported orthophoto after post-processing from MAVinci Desktop flight planning software (Images ... 2011)

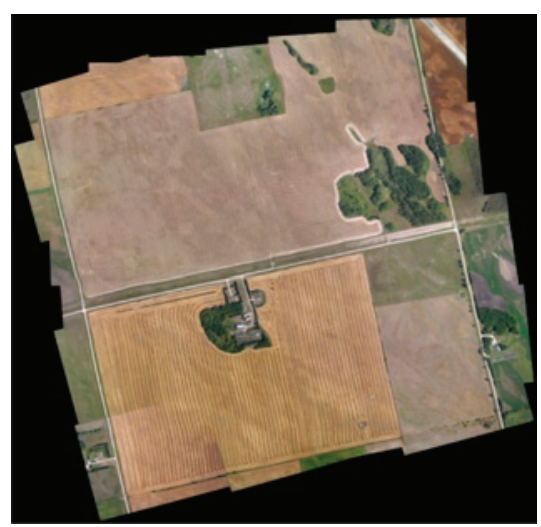

Fig. 9. Orthographic image after post-processing (Images ... 2011)

From the photos taken, the software can automatically create a three-dimensional model of the area covered (Fig. 10).

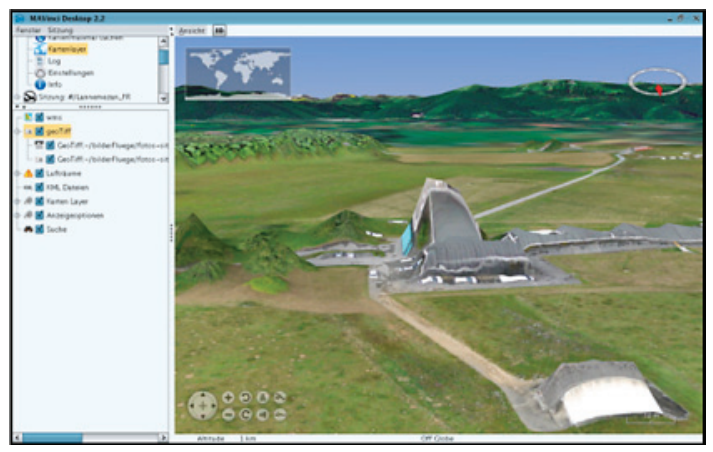

Fig. 10. Imported 3D model after post processing from MAVinci Desktop flight planning software (Images ... 2011)

\section{Application of result}

Any data collected with a UAV can be very useful information for any farmer. Depending on the equipment used, it is possible to get various images that provide important information for future decision making. Besides high-resolution orthophotos, it is possible to make multispectral photographs (Fig. 11) and hyper-spectral images, which allow one not only to assess crop management in general terms, but also to determine the presence of disease and the adverse effects of pesticides used before the plants are completely destroyed.

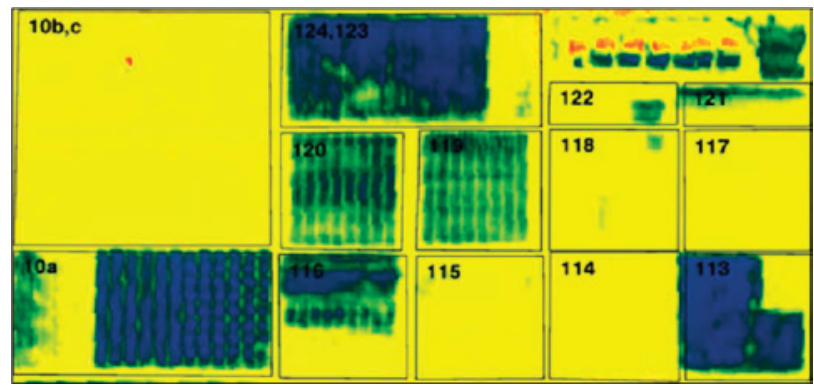

a - vegetation density (dark blues and greens indicate lush vegetation and reds show areas of bare soil) 


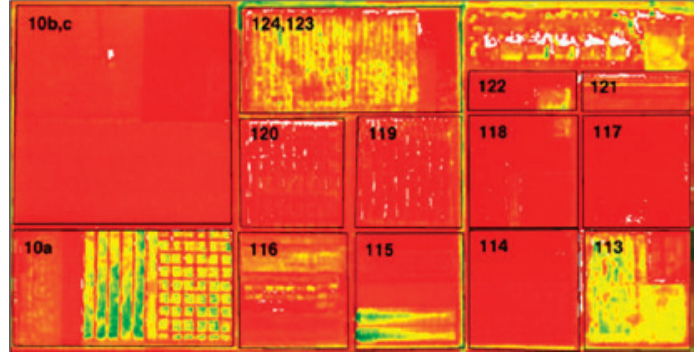

b - water deficit (greens and blues indicate wet soil and reds are dry soil)

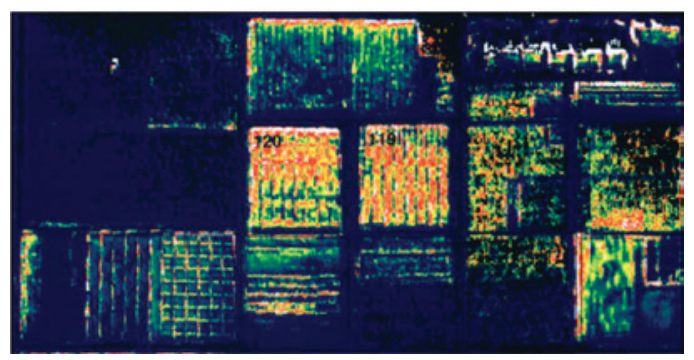

c - crop stress (indicated by red and yellow pixels)

Fig. 11. Multispectral images: (Wikipedia 2011)

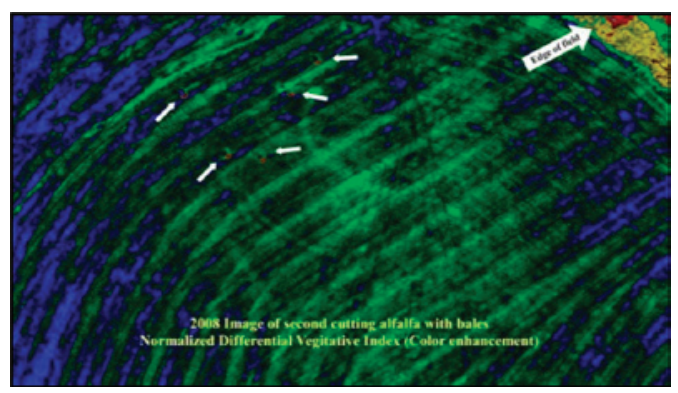

Fig. 12. Field image with calculated normalised difference vegetation index (arrows indicate the damaged plants) (Honeycutt 2011)

\section{Conclusions}

A specially equipped UAV can perform several important tasks in agriculture, including developing crop maps, monitoring vegetation, acquiring hyperspectral and multispectral images, and implementing precision agriculture.

The usage of unmanned aerial vehicles to monitor agricultural land has several advantages:

- higher-resolution images;

- no cloud disturbance (a UAV can fly below the cloud canopy);

- faster data delivery;

- easy installation;

- rechargeable electric motor;

- computerised flight plan with geographical coordinates (the exact same flight can be repeated at any time);

- ability to be equipped with different types of devices (sensors, infrared cameras, etc.);

- video recording in the air;

- ability to reach hard-to-access places;
- the data can be integrated into other systems and thus used to create geographical references;

- significantly less financial resources required.

Despite the aforementioned advantages, there are also some limitations (UAV ... 2011):

- coverage (depending on the model, the UAV has a limited flight time, hence also observation area);

- weather conditions (strong winds, heavy rainfall, etc.);

- limited payload weight.

\section{Acknowledgements}

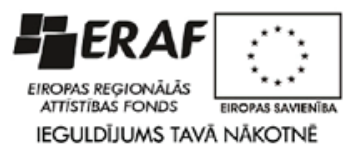

This work has been supported by the European Regional Development Fund within the project 'Development of an unmanned aircraft system and creation of the industrial prototypes of unmanned aerial vehicles for performing tasks in the Latvian national economy' No.2010/0256/ 2DP/2.1.1.1.0/10/APIA/VIAA/070.

\section{References}

Grenzdorffer, G. J.; Engel, A.; Teichert, B. 2008. The photogrammetric potential of low-cost UAVs in forestry and agriculture, in The International Archives of the Photogrammetry, Remote Sensing and Spatial Information Sciences 37. Part B1. Beijing.

Honeycutt, G. 2008. Unmanned systems down on the farm, in AUVSI (Association for Unmanned Vehicle Systems International) publications [online], [cited 20 September 2011]. Available from Internet: www.auvsi.org

Images and information about UAV systems, in MAVinci web page [online], [cited 29 September 2011]. Available from Internet: http://www.mavinci.eu

Information on the image acquisition and processing, in MosaicMill web page [online], [cited 26 September 2011]. Available from Internet: http://www.mosaicmill.com/ index.html

UAV systems, in SkyView Solutions web page [online], [cited 28 September 2011]. Available from Internet: http:// skyviewsolutions.com.au/about-us/

Urbahs, A.; Petrovs, V.; Savkovs, K., et al. 2008. Unmanned aerial vehicle design, Transport and Engineering (26): 7-11. ISSN 1407-7345.

Vilde, A.; Ruciņš, Ā.; Viesturs, D. 2008. Glabālās Pozicionēšanas Tehnologíjas Lauksaimniecībā [Global Positioning Technologies in Agriculture]. Jelgava: LLU Lauksaimniecības tehnikas zinātniskais institūts [Agriculture Machinery Research Institute] (in Latvian).

Wikipedia, 2011. Daedelus comparison, remote sensing in precision farming [online], [cited 26 September 2011]. Available from Internet: http://commons.wikimedia.org 